\title{
Global mindset: Premissa para desenvolver vantagem competitiva em mercados internacionais
}

\author{
Anelise Rebelato Mozzato e Denize Grzybovski ${ }^{1}$ \\ Universidade de Passo Fundo, UPF, Passo Fundo/RS, Brasil
}

\section{DETALHES DO ARTIGO}

\section{Histórico do Artigo:}

Recebido: 01 de Outubro de 2017

Revisado: 04 de Dezembro de 2017

Aceito: 29 de Janeiro de 2018

Disponível online: 28 de Abril de 2018

Sistema de revisão "Double blind review"

Editor Científico

Mariana Sutter

\section{Palavras-chaves:}

Global mindset

Liderança global

Vantagem competitiva

Processo de internacionalização

América Latina
RESUMO

Este ensaio teórico tem como objetivo apresentar um modelo integrativo analítico para organizações e líderes considerarem a global mindset como premissa para obtenção de vantagem competitiva em mercados internacionais. Global mindset é tema relacionado à liderança global, ainda pouco discutido teórica e empiricamente, sobretudo no Brasil. A literatura indica que é preciso desenvolver a capacidade para compreender e lidar com a complexa realidade global. Assim, a global mindset constitui-se como importante tanto para os líderes como para as organizações, pois facilita a compreensão de como as coisas são feitas, diminui a distância psíquica e facilita as conexões entre local e global. O modelo integrativo analítico é apresentado e discutido, servindo de base para pesquisas futuras, principalmente empíricas.

(C) 2018 Internext | ESPM. Todos os direitos reservados!

\section{INTRODUÇÃO}

A global mindset é tema central desse trabalho, a qual se torna cada vez mais importante no atual contexto econômico e tecnológico global. Nesse cenário, a ampliação das fronteiras nacionais representa uma mudança substancial na gestão organizacional, culminando na necessária revisão das fronteiras das empresas e também dos indivíduos que nela trabalham em busca de novas fontes de vantagem competitiva. Como referem Javidan, Steers e Hitt (2007) e Beechler e Javidan (2007), a capacidade de criar sistemas integrados em nível mundial é uma dessas novas fontes, contudo requer líderes empresariais com global mindset.

Mesmo ciente da variedade crescente de definições e abordagens sobre global mindset (Andresen; Bergdolt, 2017), apresenta-se a conceituação de Beechler e Javidan (2007, p. 152): "um conjunto de capacidades individuais de

\footnotetext{
${ }^{1}$ Contato do autor - Email: gdenize@upf.br
}

conhecimentos, cognição e atributos psicológicos, que possibilitam a indivíduo que a possui influenciar indivíduos, grupos e organizações de diversos sistemas socioculturais". Com a reflexão apresentada no artigo desenvolvido pelos autores torna-se evidente a necessidade de desenvolvimento da global mindset para a efetividade da liderança global.

Por sua vez, líderes com mentalidade global reúnem um conjunto de características e atributos para responder à complexidade e à competição em fronteiras globais (Beechler; Javidan, 2007; Javidan; Bowen; Story et al., 2014), como a visão global ampliada, adaptação aos diferentes ambientes e culturas de países diversos (Story; Barbuto, 2011; Fleury; Fleury, 2016). Normalmente, quando se realizam negócios internacionais, com uma perspectiva de espaço pessoal ampliado, adota-se um comportamento mais tolerante com outros povos e culturas para adaptar em ambientes locais (Kefalas, 1998), assim, faz-se necessário o ajustamento 
intercultural (Black, 1990; Rosal, 2015). Como afirmam Javidan e Walker (2013) as interações globais para negócios são inúmeras e imprevisíveis, necessitando de preparação para tal.

Global mindset é tema emergente ainda pouco debatido tanto teórico como empiricamente, principalmente no Brasil. Em nível internacional, Javidan e Mansour (2013) publicaram o handbook Developing your global mindset como uma tentativa de auxiliar pesquisadores e praticantes (gestores e executivos) a compreender a temática no contexto contemporâneo, com fronteiras culturais tênues, que impõe desafios na construção de global mindset. Andresen e Bergdolt (2017) apresentam definições e diferenciações claras a global mindset, considerando que ela é altamente relevante para o gerenciamento estratégico e normativo. Nacionalmente, pesquisadores da Fundação Getúlio Vargas (FGV), especialmente Maria Tereza Leme Fleury, vem desenvolvendo pesquisas sobre a temática junto aos seus pares. Os resultados de tais pesquisa, as quais também trabalham com outras questões relacionadas a global mindset (internacionalização, empresas globais, competências globais, multinacionais brasileiras) são divulgados por meio de publicações diversas, tanto nacionais como internacionais. Maria Tereza Leme Fleury e outros pesquisadores, a exemplo do anuário de pesquisa publicado na FGExecutivo em 2015-2016, relatam tais estudos que estão em constante desenvolvimento.

Entretanto, entende-se que ainda há espaço para mais pesquisas, observando-se uma lacuna de pesquisa no que tange ao necessário desenvolvimento da global mindset por líderes que atuam em mercados internacionais, por mais que alguns estudos mais recentes já estão tangenciando essa relação, a exemplo do desenvolvido por Egel e Fry (2017), em que os autores afirmam sobre a necessidade de "cultivar" a global mindset por meio das lideranças. Portanto, o pressuposto teórico é de que é possível desenvolver líderes e empresas para compreender e lidar com a complexa realidade mundial. Nessa lógica, como afirmam Ramsey et al. (2017), líderes globais, com altos níveis de inteligência cultural, são mais capazes de entender as diferenças culturais da realidade mundial, adequando-se ao comportamento.

Deste modo, este ensaio teórico de natureza argumentativa tem como objetivo apresentar um modelo integrativo para organizações e líderes considerarem a global mindset como premissa para desenvolver vantagem competitiva em mercados internacionais. A escolha do eixo teórico e do respectivo referencial para este ensaio teórico foi realizada com base em pesquisa nas bases de dados internacionais e nacionais, culminando no estado da arte. Assim, a lacuna teórica ficou evidenciada, possibilitando a proposição do modelo integrativo analítico, o qual poderá ser útil para futuras pesquisas, sobretudo empíricas.

Para o melhor entendimento do desenvolvimento deste ensaio teórico apresenta-se a forma como está estruturado. Após essa introdução, como resultado de pesquisa nas bases de dados, esboçam-se questões relacionadas ao contexto empresarial de internacionalização no qual a global mindset é apresentada como possibilidade para o posicionamento estratégico global, bem como a dimensão individual e organizacional da global mindset e uma dimensão essencial da liderança global. Assim, numa outra subseção foi possível a apresentação de um modelo integrativo para a análise da global mindset em mercados internacionais. Por último, conclusões do estudo são apresentadas, momento no qual são elencadas as principais contribuições do ensaio teórico, além de que as limitações são expostas e as implicações para pesquisas futuras apontadas.

\section{CONTEXTO EMPRESARIAL INTERNACIONALIZADO}

O ambiente empresarial atual é mais bem descrito pelas mudanças que ocorrem nas dimensões econômicas e tecnológicas, as quais provocam transformações nas dimensões políticas e culturais em nível global (Javidan; Steers; Mitt, 2007). O desaparecimento das fronteiras tradicionais para a realização de negócios se traduzem num ambiente global, forçando as organizações e seus líderes a não pensarem somente de forma local, para não criarem dependência de um único mercado, mas enfrentar os desafios que a globalização impõe. "O ambiente empresarial internacional proporciona para empresas oportunidades sem precedentes, mas também desafios formidáveis porque globalização é uma manifestação de complexidade" (LANE; Maznevski; Mendenhall, 2004 apud Beechler; Javidan, 2007, p. 132).

Dessa forma, administrar a complexidade requer novas posturas, novos pensamentos, novas formas 
de organização e, principalmente, multiplicidade de ações. Como sugere Lasserre (2003 apud Beechler; Javidan, 2007, p. 132), explorar oportunidades globais exige o desenvolvimento de estratégias globais efetivas por parte das organizações. A internacionalização acontece de maneira intensa. Também as organizações dos mercados emergentes necessitam repensar a forma de relacionamento com outros países (Bandeira-de-Mello, et al., 2016), pois se, a princípio, parecem não ter possibilidade de internacionalização, podem surpreender, a exemplo da Embraer, citado por Urban e Fleury (2005).

Diante do contexto tal como se apresenta, faz-se necessário que as empresas pensem em possibilidades além do mercado doméstico (Reis; Fleury, 2010) e, para tanto, o temor pelo desconhecido e pelos riscos envolvidos num processo de internacionalização precisam ser superados. Os estudos desenvolvidos por Miocevic e CrnjakKaranovic (2012) e Felicio, Caldeirinha e Rodrigues (2012) revelam que a global mindset é um fator chave no processo de internacionalização das pequenas e médias empresas, pois inclui três capitais: (a) capital intelectual global; (b) capital psicológico global; (c) capital social global. Tais capitais são explorados teoricamente por Javidan e Mansour (2013) e compreendem componentes cognitivos, afetivos e comportamentais importantes.

A forte concorrência mundial e a necessidade de entrar em novos mercados não aceitam mais o pensar local, exigindo postura global por parte das organizações. "Vive-se hoje em um mundo interconectado, onde eventos em quaisquer lugares afetarão negócios locais, o que denota a importância do tema, pois pode residir nele à sobrevivência e consolidação da organização no âmbito global e local" (Winck et al., 2016, p.46).

A internacionalização é fato e tem se intensificado gradativamente nos últimos anos. Como referem Beechler e Javidan (2007), os avanços tecnológicos, a redução de custos para viagens, a abertura das fronteiras políticas e a crescente importância dos bens materiais têm oportunizado que um número crescente de organizações trabalhe em mercados internacionais. Diante do contexto, Ghemawat (2007) aponta a necessidade da redefinição de uma estratégia global sustentável, visto que ao se atravessar fronteiras deve-se reconhecer e trabalhar as inúmeras diferenças inerentes a cada mercado, as quais podem se constituir em verdadeiras lacunas, como as culturais, administrativas, geográficas, econômicas etc.

Para lidar com a internacionalização num contexto de globalização, a empresa necessita desenvolver uma mentalidade transnacional, para alcançar economia de escala e flexibilidade locais simultaneamente (Reis; Fleury, 2010). Na interpretação de Bouquet (2005), há relações entre estruturas de atenção e tomadas de decisão na alta gerência e a maneira pela qual os gestores direcionam sua atenção a determinados assuntos globais (atenção global) acaba por configurar a estratégia global da empresa.

Torna-se evidente que muitos desafios devem ser superados para o sucesso da internacionalização, dentre os quais se pode citar a questão cultural como muito importante. Dada a constatação da interferência direta da cultura nos sistemas de negócio, essa questão precisa ser levada em conta à medida que os negócios internacionais se intensificam. Dessa forma, merece discussão o impacto da cultura sobre a motivação das pessoas, a gestão das pessoas, as formas de liderança e o planejamento estratégico. Como afirmam Tanure e Duarte (2006), deve-se tomar o cuidado para não se ficar na "superfície cultural", o que é muito perigoso e pode gerar muitos desencontros e dissabores.

No que tange à definição de cultura, como referem Beechler e Javidan (2007), apesar da divergência de visões, há certo acordo geral de que a formação (construção) cultural recorre aos sistemas cognitivos e comportamentais que são moldados como resultado de experiências individuais. $\mathrm{Na}$ medida em que os indivíduos compartilham experiências comuns, formam semelhanças de perfil cognitivo e comportamental, tudo influenciado por fatores individuais de personalidade; dessa forma, até mesmo dentro de uma mesma cultura há uma gama de diferenças individuais. Os autores afirmam que, a cultura de uma sociedade reflete algum tipo de acordo coletivo tanto em significados como em interpretações, a qual promove influências sociais por meio de "um jogo comportamental convincente, afetivo, e orientado de atitudes e valores para os envolvidos" (House; Wright; Aditya, 1997 Apud Beechler; Javidan, 2007, p.144).

Tanure e Duarte (2006) destacam a necessidade de melhorar a sensibilidade cultural dos executivos, que é um processo complexo porque envolve questões individuais e não se pode pensar num 
padrão único de ação. Como ponto de partida, tanto a cultura de origem como a de destino devem ser bem conhecidas e da maneira menos estereotipada possível, com a aceitação das diferenças. Como exemplo os autores destacam o fato de os brasileiros intitularem-se e também serem descritos como muito calorosos e receptivos, porém essa não é a visão que outros povos possuem em relação a esses, pois o inglês tende a ver essa atitude como muito invasiva e o finlandês, como desconcertante.

Como são os líderes que trabalham com os indivíduos e grupos, para serem bem sucedidos, necessitam agir de modo culturalmente aceitáveis, o que repercutirá no sucesso organizacional. O líder global, necessariamente, tem de conhecer aspectos culturais das pessoas com quem está trabalhando, pois só dessa forma terá sucesso em seu processo de liderança. Ainda, a diversidade cultural necessita ser respeitada (Urban; Fleury, 2005; Tanure; Duarte, 2006; Rosal, 2015; Calderón; Guedes; Carvalho, 2016). Somente com o "conhecimento dos valores mais fundamentais, tanto da própria cultura quanto do país-alvo, na prática dos negócios internacionais permite ao líder distinguir como, quando e por que as diferenças são importantes nas diversas esferas desses negócios. Isso é fundamental em todas as fases do processo de internacionalização, desde a escolha do parceiro até, no caso de uma aquisição, a gestão de todo o processo de mudança" (Tanure; Duarte, 2006).

A interferência das questões culturais nos negócios internacionalizados é fato. Por isso, "encontros culturais precisam ser preparados, planejados, não acontecem por acaso. O planejamento pressupõe, em primeiro lugar, conhecer e dar um sentido às diferenças culturais e, em particular, à cultura do próprio País" (Tanure; Duarte, 2006, p.29). Esse se configura num bom início para o desenvolvimento do global mindset, evidenciando que tanto o conhecimento como a aprendizagem são conceitos fundamentais na internacionalização.

A global mindset configura-se como uma dimensão muito importante na gestão dos processos de internacionalização (Reis; Fleury, 2010; Kuada, 2016), em especial porque requer capacidades organizacionais específicas, como descritas por Jeannet (2000): habilidades analíticas globais, capacidade de avaliar mercados globais, habilidades para a formação de estratégias globais. Em suma, pode-se afirmar que internacionalização pode criar oportunidades promissoras para as organizações. No entanto, para que as experiências sejam positivas, muitos aspectos devem ser observados e trabalhados, como a questão das diferenças culturais enfatizada.

\section{GLOBAL MINDSET COMO POSSIBILIDADE PARA O POSICIONAMENTO ESTRATÉGICO GLOBAL}

\subsection{Global mindset: individual e organizacional}

A organização que possui posicionamento global ou que o pretende atingir, demanda a global mindset. Javidan, Steers e Hitt (2007) explicam que os efeitos da globalização são universais, levando as empresas à novas configurações sociais, políticas e modelos de negócio (Story et al., 2014), o que culmina na exigência de líderes preparados para atuarem nesse novo cenário (Javidan; Mansour, 2013), constituindose global mindset como muito importante na gestão organizacional. Os referidos autores salientam a importância da global mindset como vantagem competitiva, sugerindo a melhor compreensão da sua base teórica e práticas relevantes.

O processo de internacionalização em ambiente global exige tanto das organizações como dos indivíduos o desenvolvimento da global mindset. No entanto, o que significa uma mentalidade global em um nível individual? Estudo empírico desenvolvido por Dekker, Jansen e Vinkenburg (2005) revela que o indivíduo com global mindset tem como potencialidade estruturar a complexa realidade mundial, orientando o comportamento adequado, com visíveis habilidades interpessoais; possui, ainda, uma perspectiva mais ampla sobre o mundo, mercados, organizações e pessoas.

O global mindset no nível individual refere-se à predisposição de uma pessoa para responder aos processos inerentes à globalização, entendendo, respeitando e simplificando (com responsabilidade) a realidade social. Govindarajan e Gupta (2002) e Maznevski e Pista (2004 apud Beechler; Javidan, 2007) referem que um indivíduo com global mindset tem consciência da diversidade dos negócios através de países, culturas e mercados, apresentando habilidade para desenvolver e interpretar critérios e maneiras de desempenho empresarial, independentemente das suposições de um único país, cultura ou contexto. Assim, tem a habilidade para sintetizar essa diversidade e implementar 
critérios diferenciados em diferentes países, culturas e contextos.

O desenvolvimento individual, de líderes, também requer tempo, evoluindo aos poucos, visto que envolve pessoas; logo, mudanças efetivas em termos comportamentais demandam tempo e esforço. Neves e Tomei (2016) confirmam que o global mindset afeta o comportamento dos líderes, razão pela qual entendem que se deve investir em programas de desenvolvimento de lideranças.

Dado o exposto, torna-se evidente a necessidade do desenvolvimento de uma mentalidade empresarial global, com estratégias globais e também um grupo de líderes com mentalidade global para que uma empresa possa competir com êxito em mercados mundiais. Javidan, Steers e Hitt (2007), diante dessa evidente mudança nas fronteiras dos negócios, exige-se que os líderes organizacionais desenvolvam e utilizem o global mindset. Como afirmam Story e Barbuto (2011), a visão global ampliada facilita a adaptação aos diferentes países com culturas específicas.

E o que significa a global mindset organizacional? ela é observada por meio das estratégias definidas, das suas competências essenciais estabelecidas e da cultura corporativa predominante. Quanto mais bem desenvolvida a mentalidade global corporativa, mais fácil se torna a entrada em novos mercados, expandindo-se em arenas competitivas. No entanto, o desenvolvimento de uma mentalidade corporativa global forte é um processo que exige estratégia bem definida e coerente em longo prazo, conduzida pelos gestores das diferentes áreas organizacionais estratégicas.

Visando à global mindset organizacional, percebese a necessidade do desenvolvimento da global mindset dos indivíduos que nela trabalham, sobretudo, dos líderes. Assim como Borini e Fleury (2011), Winck et al. (2016) também ressaltam a relevância do desenvolvimento das competências de líderes globais. " A adaptação proveniente desse desenvolvimento é o que vai garantir a eficiência da empresa em um âmbito internacional ou local e a aceitabilidade do líder global por seus liderados em quaisquer ambientes" (Winck et al., 2016, p.46).

Dado o exposto, entende-se porque os gestores da área de gestão de pessoas, os consultores, coachings e pesquisadores buscam definir parâmetros tanto para a liderança global como para a global mindset. A liderança global e a global mindset contribuem, sobremaneira, na definição de como devem ser desenvolvidas as estratégias tanto em nível individual como organizacional (Osland; Bird; Mendenhall; Osland, 2012).

Para Plummer (2001), até certo ponto, todos os indivíduos são etnocêntricos e culturalmente míopes, necessitando aumentar suas lentes pelas quais veem o mundo, visando tornarem-se culturalmente mais sensíveis. Tal sensibilidade facilita o necessário ajustamento intercultural, o qual se dá, como refere Black (1990), quando o expatriado tem conforto psicológico em relação a realidade do país hospedeiro.

Em virtude da importância da global mindset, parece natural se pensar em como desenvolvê-la. Nesse sentido, por mais que existem vários processos cognitivos para tanto (leituras, filmes, capacidade conectiva, via internet, MBAs, etc), nada substitui as viagens. Estas possibilitam a convivência com as diferentes culturas, desenvolver novas experiências em outros países e aproximar-se de pessoas de diferentes origens, abrindo a possibilidade para o líder desenvolver uma perspectiva mais ampla sobre o mundo, os mercados, as empresas e as pessoas. Blomstermo e Sharma (2003) destacam que as investigações a respeito do processo de internacionalização de organizações evidenciam o desenvolvimento experiencial do líder como fundamental.

Assim define-se o líder global como flexível o suficiente para ampliar o seu mapa cognitivo, facilitando o enfrentamento das adversidades advindas de diferentes contextos e estando aberto aos relacionamentos com diferentes pessoas em constante processo de aprendizagem, a qual deve ser buscada por meio de processos cognitivos variados, ajustando-se culturalmente.

Outra questão importante a se destacar nesse sentido é que não basta uma forte formação acadêmica para os líderes desenvolverem global mindset. Vista como uma competência faz-se necessário também, o desenvolvimento de competências em forma de ação, não só como estoque de recursos (Ruas, 2001). Diante do exposto, pode-se dizer que a global mindset constitui-se numa forma de ser segundo uma perspectiva mais ampla, global. Dessa forma, se a organização tem como objetivo trabalhar globalmente, necessariamente 
tem de pensar em cultivar e desenvolver o seu global mindset e de seus líderes.

Com base no exposto por vários autores aqui trabalhados, entre as questões que podem ajudar no desenvolvimento da global mindset citam-se: composição forte na administração superior, gestão com capacidade para refletir operações globais; forte ênfase nas estratégias definidas, apresentando-se como mais dinâmicas; investimento em capacitação e desenvolvimento profissional, aliado a um sólido plano de carreira, que privilegie o aprendizado em várias funções, empresas e países. Tanure, Cyrino e Penido (2005) destacam a implementação de sólidos planos de carreira internacionais como uma das ações mais importantes; motivação para vivências variadas (viagens, cursos, leituras diversas, atividades culturais) em diferentes culturas; desenvolvimento de redes de colaboração empresarial, tanto internamente como fora da corporação (parceiros, fornecedores, clientes, instituições de pesquisa e outros).

A curiosidade também aparece como facilitadora do desenvolvimento do global mindset. Quando o indivíduo aumenta sua curiosidade sobre o mundo, procurando entender as peculiaridades mundiais, ocorre uma ampliação dos horizontes do indivíduo, interligando-o com diferentes realidades. Outra questão importante que emerge nesse sentido é a capacidade do líder de estabelecer um bom networking, o que também é facilitado pela tecnologia da informação.

Como componentes críticos do global mindset, Beechler e Javidan (2007) apontam os capitais intelectual global, psicológico global e social global. O primeiro, o capital intelectual global, refere-se ao intelecto e à capacidade cognitiva do líder, a qual impacta diretamente nos conhecimentos globais do contexto atuado, reconhecendo a complexidade envolvida e desenvolvendo, para tanto, uma perspicácia cultural. O capital psicológico global, segundo componente, está relacionado ao estado psicológico desenvolvido em função da necessária autoconfiança, otimismo, curiosidade, resiliência e persistência, além se uma série de outros atributos. Por fim, o terceiro, o capital social global, refere-se aos relacionamentos efetivados tanto dentro como fora da empresa, refletindo a habilidade dos indivíduos para garantir sucesso em outras estruturas sociais em razão da habilidade para conectar e trabalhar com pessoas de diferentes culturas e países, mantendo relações confiantes com outros.

Cabe salientar que uma análise profunda desses três fatores críticos apresentados pelos autores revela a complexidade envolvida na global mindset. Isso evidencia o grande desafio para a liderança global, visto que a global mindset constitui-se como dimensão essencial da vantagem competitiva, apresentando-se como ferramenta importante para líderes mais suscetíveis a conduzirem suas empresas aos mercados internacionais (Javidan; Steers; Hitt, 2007).

Em artigo intitulado "Cross-border transfer of knowledge: cultural lessons from project GLOBE", Javidan et al. (2005) abordam a questão da complexidade e dos possíveis obstáculos na transferência do conhecimento nos negócios internacionalizados. Salientam que os negócios que são efetivados além da cultura de origem enfrentam desafios extras, normalmente com barreiras aumentadas. No entanto, afirmam que não são as diferenças culturais que criam problemas, e sim, a forma como as diferenças culturais são administradas. Os autores afirmam que os líderes não devem recuar diante dessas diferenças, mas serem pró-ativos, aproximando-se sistematicamente das diferenças culturais. Para isso, devem ter em mente que o sucesso da transferência do conhecimento exige a definição de metas comuns entre os envolvidos, discussão a respeito dos desafios culturais, tratando todo o processo de transferência de conhecimento como uma oportunidade de aprendizagem que facilitará o processo seguinte.

O artigo ainda apresenta o Project GLOBE e seus resultados como ferramenta útil para os executivos estarem mais preparados para os desafios que terão de enfrentar com os negócios globais. Project GLOBE é um programa de pesquisa global realizada por mais de dezesseis anos, que tem como principal objetivo estudar (olhar) a variação cultural em diferentes países (61 países), constituindo-se em fator importante para administração organizacional e liderança global (House; Javidan; Dorfman, 2001; Javidan et. al., 2005; Javidan; Steers; Hitt, 2007; Javidan; Mansour, 2013; Story et al., 2014). Nesse sentido, os autores apresentam as nove dimensões culturais propostas pelo Project GLOBE, com suas respectivas análises dos valores culturais, como uma ferramenta para ajudar executivos a entender as semelhanças e diferenças entre as várias culturas 
mundiais, levando à pró-atividade e à aproximação construtiva, que auxiliam na solução de assuntos relacionados às fronteiras culturais.

\subsection{Global mindset: \\ Dimensão essencial da liderança global}

Diante do exposto, torna-se evidente que o mercado cada vez mais vai exigir pessoas líderes capazes de pensar com mentalidade global. O líder global é capaz de administrar uma empresa integrada a diferentes fronteiras, pautadas por diferentes sistemas culturais, econômicos, sociais e jurídicos, sabendo trabalhar em ambientes múltiplos, diminuindo a distância psíquica. Beechler e Javidan (2007) mencionam tanto a necessidade de líderes globais como a falta deles no mercado, dificultando assim, relações e negociações globais.

A eficiência e eficácia de um líder têm sido estudadas extensivamente a partir de diferentes perspectivas, mas a dimensão da global mindset ainda se apresenta incipiente. Neste ensaio teórico, que tem como foco central a perspectiva de líder global, admite-se "a essência da liderança global, como em liderança genérica, é influenciar outros para contribuírem em direção ao compartilhamento de algumas metas comuns" (Javidan; Steers; Hitt, 2007, p 152). Os líderes globais precisam influenciar indivíduos com diferentes representações sociopolítico-cultural.

Nesse sentido, descreve-se um líder mundial como uma pessoa que toma frente nas decisões gerenciais em negócios globais, transmite uma visão compartilhada igualmente global, inspirando e motivando a equipe de trabalho para desenvolver a global mindset (Kuada, 2016). Para tanto, possui uma visão multicultural, conseguindo coordenar os seus subordinados para o desenvolvimento das atividades necessárias, independentemente da orientação sociopolítico-cultural. Como bem pontuam Beechler e Javidan (2007), Javidan e Bowen (2013) e Story et al. (2014), os líderes com mentalidade global reúnem um conjunto de características e atributos para responder à comple-xidade e à competição em fronteiras globais, só o complexo comportamento humano pode dar conta das complexas demandas do ambiente global.

A liderança global é descrita por Beechler e Javidan (2007, p.140) como um "processo de influenciar indivíduos, grupos e organizações (dentro e fora dos limites da organização global) representando diversos sistemas cultural-politicoinstitutional para contribuir com a realização das metas globais da organização". Contudo, há um aumento da complexidade inerente à liderança global (Beechler; Javidan, 2007; Javidan; Walker, 2013), a qual pode estar relacionada à necessidade de maior compreensão cultural e de obter conhecimentos diversos, que vão além das suas funções específicas e nações; limitações mais frequentes nas tomadas de decisão em função dos limites nacional e organizacional; aumento dos stakeholders para considerar nas tomadas de decisões; níveis mais elevados e diferentes tipos de tensões no trabalho; ambiguidade elevada e dilemas éticos mais desafiadores.

Por mais que autores procuraram definir as competências necessárias ao global mindset, englobando os conhecimentos, as habilidades e as atitudes, acredita-se que falar em atributos ou dimensões seja mais propício. Ao se falar em competências, tem-se de levar em consideração as competências organizacionais como já pré-definidas, o que é muito importante para estudos de casos específicos. Contudo, em razão do caráter teórico e geral deste ensaio, falar em atributos gerais de uma liderança global parece mais apropriado.

Também não se tem como pretensão trabalhar com uma lista enorme de atributos de forma descritiva e normativa, por mais que se listem alguns como orientadores e sintetizadores dos aspectos abordados neste trabalho. Pretende-se, sim, apenas tratar dos atributos considerados inerentes à liderança global, justamente para não incorrer no mesmo "erro" quanto às listas de competências sobre liderança global, as quais são praticamente infinitas, chegando ao ponto de se tornarem inúteis (Beechler; Javidan, 2007).

Beechler e Javidan (2007) tratam de dimensões que identificam uma liderança global, as quais foram sugeridas como resultado de pesquisas realizadas por alguns pesquisadores e também por eles próprios, principalmente daqueles das pesquisas do project GLOBE. Entre as pesquisas realizadas e publicadas por outros autores, citam a pesquisa realizada por Goldsmith, Greenberg, Robertson e Hu-Chan (2003), que identificaram doze dimensões para liderança global: integridade, diálogo construtivo, visão compartilhada, pessoas em desenvolvimento, construindo parcerias, compartilhando liderança, empowerment, pensando globalmente, apreciando 
diversidade, compreensão tecnológica, satisfação com cliente e mantendo vantagem competitiva.

O líder global apresenta o comportamento de desenvolvimento e ação com uma visão global na busca da manutenção da vantagem competitiva das organizações à qual pertencem. Essa visão global constitui-se num conjunto de atributos individuais que permitem que um indivíduo possa influenciar outros indivíduos, grupos de pessoas e organizações em diferentes Posições Socio-Economico-Culturais (Javidan; Steers; Hitt, 2007). Pode-se dizer que esse líder é um cosmopolita, o qual diminui a distância psíquica, ajustando-se interculturalmente.

Também vale salientar a importância do entendimento compartilhado entre líder global e a sua equipe de trabalho, pois só compartilhando o entendimento é que a interação toma significado, em razão do necessário entendimento coletivo para o desenvolvimento do trabalho (Sanberg; Targama, 2007). Assim, a criação de identidade com o trabalho é facilitada, culminando em maior autonomia, aspectos importantes para a formação do líder global.

Em sentido semelhante, destaca-se o sensemaking (construção de significados compartilhados que definem aspectos organizacionais), apontado como significativo quando se trata de uma leitura das variáveis organizacionais em ambientes complexos, nos quais o compartilhamento de informações necessita ser facilitado, melhorando a interação. Portanto, quanto melhor for o sensemaking, mais facilmente serão trabalhadas as contingências objetivas e, sobretudo, subjetivas (Sandberg; Targama, 2007). Diante do exposto, percebe-se a importância do sensemaking, a sua interferência na cultura organizacional, sendo, ainda básico (primordial) para a gestão do conhecimento, visto que pode ser tratado como construção de sentido (materialização de resultados), como referem Weick, Sutcliffe e Obstfeld (2005). Os autores destacam que, diante da complexidade, busca-se a construção de significados importantes e que fazem sentido para as pessoas e as organizações. Dessa forma, o sensemaking "organiza" o fluxo das informações e acontecimentos por meio da combinação de modelos mentais e constrói os significados compartilhados que definem aspectos organizacionais. Para tanto, a linguagem (comunicação) assume importante papel.
Também se destaca o empreendedorismo como um atributo indispensável ao líder global, visto que, de acordo com Hittet et al. (2001), o empreendedor procura identificar e explorar oportunidades empresariais, essas tanto no mercado nacional como no internacional. McDouglall e Oviatt (2000 apud Hitt et al., 2001) definem o empreendedor internacional como inovador, pró-ativo com comportamento para assumir riscos através dos limites nacionais e está direcionado para criar valor para as organizações. No que tange ao empreendedorismo e às diferentes culturais, Lee e Peterson (2000) afirmam que existe diferença efetiva entre diferenças culturas, pois é diferente a orientação empresarial em diferentes países.

Exposta uma série de características/qualidades/ capacidades requeridas a um líder global, apresentase a Tabela 1 como uma tentativa de sintetização, o qual reúne diversos dos atributos/dimensões encontrados na literatura. Contudo, cabe salientar que, por mais que não se tenha como pretensão colocá-los em ordem de importância, a global mindset aparece em primeiro lugar e merece destaque, até em razão de ser o foco principal deste estudo, além de sua grande importância já destacada neste Ensaio Teórico. No entanto, cabe enfatizar que outras capacidades comportamentais, mencionadas ou não aqui, também merecem atenção.

Tab. 1

Atributos e dimensões da liderança global

\begin{tabular}{l}
\hline ATRIBUTOS/DIMENSÕES DO LIDER GLOBAL \\
\hline Global mindset \\
Capacidade de liderança \\
Inquisitiveness \\
Sensibilidade e apreciação à diversidade cultural \\
Capacidade de ajustamento multicultural \\
Curiosidade \\
Visão ampliada de cenários \\
Tolerância e saber lidar com paradoxos \\
Capacidade em estabelecer um bom networking \\
Entendimento geopolítico \\
Conhecimentos específicos em direito e comércio internacionais \\
Capacidade de adaptação a situações adversas \\
Understanding \\
Sensemaking \\
Flexibilidade \\
Comunicação facilitada \\
Comportamento empreendedor \\
Atitude cosmopolita \\
Criatividade \\
Compreensão tecnológica \\
Pró-atividade
\end{tabular}

Fonte: Elaborado pelas autoras 
Mesmo que se tenha destacado a global mindset, esta não se constitui em condição única (único atributo) para liderança global (kedia; mukherji, 1999), porque há uma série de desafios envolvidos na liderança global. Portanto, para que os líderes globais obtenham sucesso, há a necessidade do constante aprendizado e desenvolvimento, pois a global mindset é parte importante desse arcabouço complexo do invólucro da liderança global.

Contudo, salienta-se ainda que não se teve como pretensão o "mapeamento" de competências necessárias a um líder global, trabalho já desenvolvido por McCall e Hollenbeck (2002). Muito menos se quis apresentar conselhos para o sucesso de executivos, os quais são apresentados em outros trabalhos, como o desenvolvido por Brown (2008) e intitulado como $O$ executivo global: conselhos práticos para o sucesso em um mercado transcultural.

\section{MODELO INTEGRATIVO PARA ANÁLISE DA GLOBAL MINDSET}

Ciente de que a global mindset é altamente relevante para o gerenciamento estratégico em nível global (Andresen; Bergdolt, 2017), entende-se assim como Egel e Fry (2017), que os líderes necessitam desenvolvê-la para atuação em mercados internacionais. Portanto, modelo integrativo é proposto para a análise da global mindset em mercados internacionais (Figura 1). Neste, a global mindset é considerada premissa para desenvolver vantagem competitiva para as organizações globais, facilitando as conexões entre o local e o global, diminuindo as distâncias psíquicas.

Como evidenciado na discussão teórica aqui apresentada, a figura demonstra que pessoas e organizações que trabalham com a global mindset demonstram melhor compreensão de como as coisas são feitas em diferentes partes do mundo. Assim, diminui-se a distância psíquica aumentando a capacidade de se estabelecer conexões mais efetivas e de sucesso. Nesse sentido, os componentes críticos do global mindset (capital intelectual global, capital psicológico global e capital social global) necessitam ser trabalhados pelos líderes globais na dimensão essencial da liderança global, pois tem potencial para gerar vantagem competitiva no processo de internacionalização por meio da criação de sistemas integrados em nível mundial.

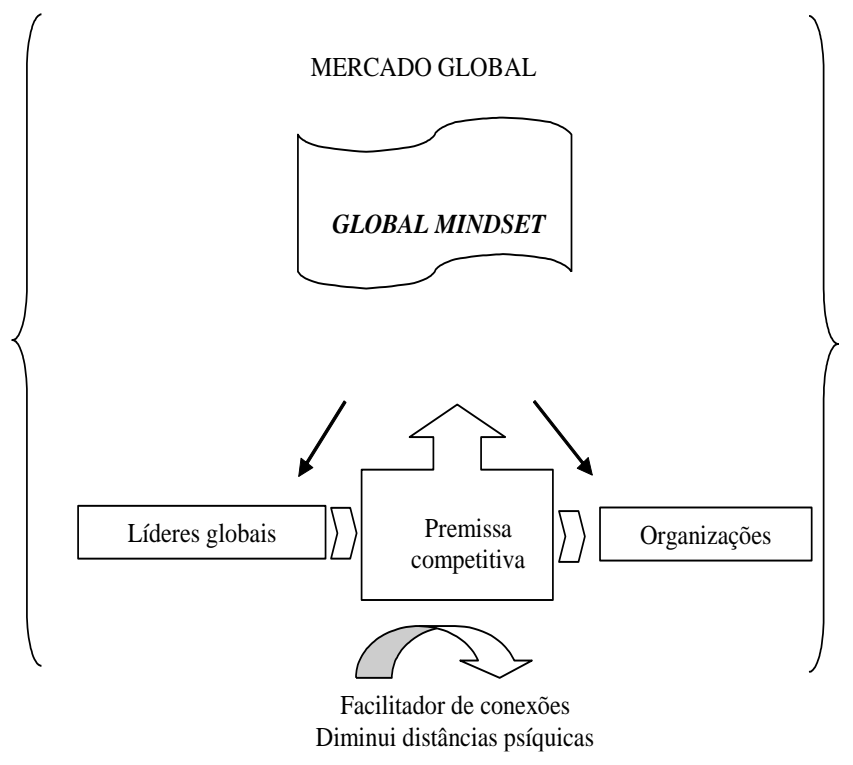

Fig. 1

Global mindset como premissa competitiva para organizações e líderes globais

Fonte: Elaborado pelas autoras

Como bem destacam Javidan, Steers e Hitt (2007), a global mindset constitui-se num grande desafio para a liderança global, visto ser uma dimensão essencial da vantagem competitiva nos mercados globais. Portanto, a global mindset foca em resultados estratégicos importantes para os líderes e organizações globais.

\section{CONCLUSÕES}

A globalização, com a consequente concorrência global, exige um modelo de gestão com global mindset, ou seja, organizações e pessoas com visão mais ampliada, global. Essa visão global torna-se ainda mais importante no atual cenário de crise econômica mundial, exigindo um entendimento do que está ocorrendo e a consequente perspicácia para trabalhar em ambientes turbulentos e incertos. Nesse sentido, Kuada (2016) fala de como implementar a global mindset nas práticas de gestão de uma organização.

Para estar posicionada como uma organização bem-sucedida na atualidade faz-se necessária a exploração de novas oportunidades e o enfrentamento dos desafios que as acompanham, inclusive o de ser uma empresa global. Para tanto, as organizações dependem crucialmente das pessoas que as integram e de suas capacidades, sobretudo das que ocupam posição de liderança. Como referem Fleury e Fleury (2016) ao desenvolverem a 
mentalidade global, os executivos ajudam a organização a se posicionar mais competitivamente.

Dessa forma, tanto empresa como indivíduos, ao observarem e interpretarem o contexto dinâmico e multifacetado demandam a construção da global mindset como uma forma de enfrentar as dificuldades humanas e culturais, mas também como uma prática que promove resultados efetivos na tentativa de construir vantagem competitiva. Administrar a complexidade requer novas posturas, novos pensamentos, novas formas de organização e, principalmente, multiplicidade de ações.

Torna-se evidente o grande desafio e o longo caminho que se precisa trilhar para o melhor entendimento teórico e desenvolvimento prático da global mindset. No entanto, com a proposição do modelo integrativo e o debate aqui estabelecido acredita-se estar trazendo contribuições gerenciais e também para os pesquisadores interessados no tema. O tema ainda pode ser dito como incipiente, sobretudo no Brasil, necessitando de mais estudos, principalmente empíricos. Também é percebido como positivo o fato de que a revisão teórica apresentada é baseada, quase que exclusivamente, em literatura internacional e atualizada, podendo servir de base para pesquisas futuras.

Entende-se pertinente salientar que outras questões importantes trabalhadas no escopo deste ensaio merecem maior aprofundamento, no entanto não poderiam ser tratadas aqui pelo fato de exigirem uma dedicação exclusiva em razão de sua importância. Nesse sentido, como principal limitação apresentam-se as dimensões/atributos do líder global elencadas no Quadro 1. Por fim, salienta-se que o estudo se constitui numa "base" e estímulo para futuras pesquisas mais aprofundadas, sobretudo, estudos empíricos sobre o tema e a aplicação do modelo integrativo proposto.

\section{REFERÊNCIAS}

- ANDRESEN, M.; BERGDOLT, F. A systematic literature review on the definitions of global mindset and cultural intelligence: merging two different research streams. The International Journal of Human Resource Management, v. 28, n.1, 2017.

- BANDEIRA-DE-MELLO, R.; FLEURY, M.T.L.; AVELINE, C. E. S.; GAMA, M. A. B. Unpacking the ambidesterity implementation process in the internationalization of emerging market multinationals. Journal of Business Research, v. 1, p. 1-13, 2016.
- BEECHLER, S.; JAVIDAN, M. Leading with a global mindset: The Global Mindset. Advances in International Management, v. 19, p.131-169, 2007.

- $\quad$ BLACK, J. S. The relationship of personal characteristics with the adjustment of Japanese expatriate managers. Management International Review, v.30, n.2, p.119-134, 1990.

- BLOMSTERMO, A.; SHARMA, D. D. Learning in the internationalisation process off firms. Edward Elgar Publishing, 2003.

- BORINI, F.; FLEURY, M. Development of non-local competences in foreign subsidiaries of Brazilian multinationals. European Business Review, v.23, i.1, p.106-119, 2011. DOI: 0.1108/09555341111098017

- BOUQUET, C. Building global mindsets: an attentionbased perspective. New York: Palgrave Macmillan, 2005.

- BROWN, J. F. O executivo global: conselhos práticos para o sucesso em um mercado transcultural. Porto Alegre: Bookman, 2008.

- CAlderón, P. A. L.; GUedes, A. L. M.; CARVAlHO, R. W. Gestão internacional de recursos humanos: adaptabilidade intercultura na expatriação de brasileiros. Internext - São Paulo, v.11, n. 1, p. 6-20, mai./ago. 2016.

- DEKKER, W. D.; JANSEN, P. G. W. and VINKENBURG, C. J. Dimensions of an individual global mindset, 2005.

- EGEL, E.; FRY, L.W. Cultivating a Global Mindset Through "Being-Centered" leadership. In: Judi Neal. Handbook of Personal and Organizational Transformation. USA: Springer International Publishing, 2017

- FELÍCIO, J.; CALDEIRINHA, V.; RODRIGUES, R. Global mindset and the internalization of small firms: the importance of the characteristics of entrepreneurs. International Entrepreneurship and Management Journal, v. 8, n.4, p. 467-485, 2012.

- FleURY, M.T.L.; FLEURY, A. O desenvolvimento das multinacionais brasileiras no cenário global. GVExecutivo, v. 15, n. 1, jan./jun. 2016.

- FLEURY, A. ; SHI, Y.; FERREIRA JR., S.; CORDEIRO, J.H.; FLEURY, M.T.L. O desenvolvimento de competências de multinacionais brasileiras. GV Pesquisa, anuário de pesquisa 2015-2016.

- GHEMAWAT, P. Redefining global strategy: crossing borders in a world where differences still matter. Harvard Business School Press, 2007.

- GUPTA, A.; GOVINDARAJAN, V. Cultivating a global mindset. Academy of Management Executive, v.16, n.1, p.116-126, 2002.

- $\quad$ HITT, M. A.; IRELAND, D.; CAMP, S. M.; SEXTON, D. L. Guest editors' introuction to the special issue strategic entrepreuneurship: entrepreneurial strategies for wealth creation. Strategic Management Journal, v. 22, n.6/7, p. 479-491, 2001. 
- HOUSE, R.; JAVIDAN, M.; DORFMAN, P. Project GLOBE: An Introduction. Applied Psychology: An International Review, v. 50, n.4, p. 489-505, 2001.

- JAVIDAN, M.; STAHL, G. K.; BRODBECK, F.; WILDERO, C. P.M. Cross-border transfer of knowledge: cultural lessons from Project GLOBE. Academy of Management Executive, v. 19, n.2, 2005.

- JAVIDAN, M.; STEERS, R. M.; HITT, M. A. The global mindset: advances in international management. Oxford: Elsevier JAI, 2007.

- JAVIDAN, M.; BOWEN, D. The 'Global Mindset' of managers: What it is, why it matters, and how to develop it. Organizational Dynamics, v. 42, n. 2, p. 145-155, 2013

- JAVIDAN, M.; WALKER, J. L. Developing your global mindset: the handbook for successful global leaders. Edina: Beaver's Pond, 2013.

- JEANNET, J. P. Managing with a global mindset. London: Times/Prentice Hall, 2000.

- $\quad$ KEDIA, B.; MUKHERJI, A. Global managers: developing a mindset for global competitiveness. Journal of World Business, v.34, n.3, p. 230-252, 1999.

- $\quad$ KEFALAS, A. G. Think globally, act locally. Thunderbird International Business Review, v.40, n.6, p.547-562, 1998.

- KUADA, J. Global mindsets: exploration and perspectivas. USA: Routkedge, 2016.

- $\quad$ LEE, S. M.; PETERSON, S. N. Culture, entrepreneurial orientation, and global competitiveness. Journal of World Business, v. 35, p. 401-416, 2000.

- McCALL, M.; HOLLENBECK, G. Developing global executives: the lessons of international experience. Boston: Harvard Business School Press, 2002.

- MIOCEVIC, D.; CRNJAK-KARANOVIC, B. Global mindset: a cognitive driver of small and medium-sized enterprise internationalization; The case of Croatian exporters. EuroMed Journal of Business, v. 7, n.2, p. 142-160, 2012.

- $\quad$ NEVES, V.; TOMEI, P. Global mindset e comportamento da liderança. Revista IberoAmericana de Estratégia - RIAE, v. 15, n.2. April/June. 2016.

- OSLAND, J. S., BIRD, A., MENDENHALL, M.; OSLAND, A. Developing global leadership capabilities and global mindset: a review. In: STAHL, G. K. and BJÖRKMAN, I. Handbook of Research in International Human Resource Management, 2. ed. Reino Unido: Edward Elgar Publishing, 2012.

- PlUMMER, D. L. Overview of the Field of diversity management. In: __. Handbook of Diversity Management: beyond awareness to competency based learning. Laham: University Press of America. 2001. Cap. 5.

- RAMSEY, J. R.; RUTTI, R. M.; LORENZ, M. P.; BARAKAT, L, L.; SANT'ANNA, A.S. Developing global transformational leaders. Journal of World Business, v. 52, i. 4, p. 461-473, June 2017. https://doi.org/10.1016/j.jwb.2016.06.002

- REIS, G. G.; FLEURY, M. T. L. O global mindset de empresas early movers e late movers é diferente? Influências do ambiente local e do grau de internacionalização. XIII Semead na FEA-USP, Anais Semead... 2010.

- ROSAL, A.S.R. Gestão de Recursos Humanos Internacional e o Ajustamento Intercultural do Executivo Expatriado. Psic. Rev. São Paulo, v. 24, n.1, p. 121-141, 2015.

- RUAS, R. Desenvolvimento de competências gerenciais e a contribuição da aprendizagem organizacional. In FLEURY, M. T.; OLIVEIRA Jr., M (Org.). Gestão estratégica do conhecimento. São Paulo: Atlas, 2001. p.242-267.

- SANDBERG, J.; TARGAMA, A. The rise of an interpretative perspective on management. Managing Understanding in Organizations. California: Sage, 2007.

- STORY, J. S. P.; BARBUTO, J. E. Global Mindset: A Construct Clarification and Framework. Journal of Leadership \& Organizational Studies, v. 18, n. 3, p. 377-384, 2011.

- $\quad$ STORY, J. S. P., BARBUTO JR., J. E., LUTHANS, F.; BOVAIRD, J. A. Meeting the challenges of effective international HRM: analysis of the antecedents of global mindset. Human Resource Management, v. 53, n.1, p. 131-155, 2014.

- tanure, B.; DUARTE, R. G. Sensibilidade cultural. GV Executivo, v.5, n.4, 2006.

- $\quad$ TANuRE, B., CYRINO, A.; PENIDO, E. Seus executivos estão prontos para comandar lá fora? Valor Econômico - Eu e Carreira, São Paulo, 2005.

- URBAN, T. P.; FLEURY, M. T. L. Competências e internacionalização: um estudo de caso em empresa brasileira com subsidiária de produção no exterior. VIII Semead na FEA-USP, 2005.

- WEICK, K. E.; SUTCLIFFE K.M.; OBSTFELD, D. Organizing and the process of sensemaking. Organization Science, v.16, n.4, p.409-421, 2005.

- WINCK, M.F.; FROEHLICH, C.; BOHNENBERGER, M. C.; BESSI, V. G.; SCHREIBER, D. O desenvolvimento das competências e líderes globais: uma abordagem baseada nos estudos de global mindset leadership. Internext - São Paulo, v.11, n. 2, p. 35-48, mai./ago. 2016. 


\section{SOBRE OS AUTORES}

- Anelise Rebelato Mozzato é Psicóloga (UPF). Especialista em Gestão Empresarial (UFSC/UPF). Mestre em Educação (UPF). Doutora em Administração (Unisinos). Docente Permanente do Programa de PósGraduação em Administração (PPGAdm) na Faculdade de Ciências Econômicas, Administrativas e Contábeis (FEAC) na Universidade de Passo Fundo. E-mail: anerebe@upf.br

- Denize Grzybovski é Bacharel em Administração (URI Campus Erechim). Mestre em Dirección y Organización de Empresas (Universidad Museo Social Argentino/UMSA). Doutora em Administração (UFLA) com tese em empresa familiar. Docente Permanente do Programa de Pós-Graduação em Administração (PPGAdm) na Faculdade de Ciências Econômicas, Administrativas e Contábeis (FEAC) na Universidade de Passo Fundo. Professora Convidada no Programa de Pós-Graduação em Desenvolvimento Regional na Universidade Regional do Noroeste do Estado do Rio Grande do Sul (UNIJUÍ).E-mail:gdenize@upf.br 


\title{
Global mindset: Premise for developing competitive advantage in international markets
}

\author{
Anelise Rebelato Mozzato and Denize Grzybovski \\ Universidade de Passo Fundo, UPF, Passo Fundo/RS, Brazil
}

ARTICLE DETAILS
Article history:
Received: October 01, 2017
Reviewed: December 04, 2017
Accepted January 29, 2017
Available online April 28, 2018
Double Blind Review System
Scientifc Editor
Mariana Sutter

\section{Keywords:}

Global mindset

Global leadership

Competitive advantage

Internationalization process

\begin{abstract}
This theoretical paper aims to present an analytical scheme for organizations and leaders consider global mindset as a premise to develop competitive advantage in international markets. Global mindset is theme related to global leadership, yet little discussed theoretically and empirically. It is questioned whether the global mindset, as a dimension of global leadership, can generate competitive advantage in internationalization processes. The literature indicates that organizational knowledge is in itself valuable strategic resource and organizational capacity to learn is crucial for success in the global competitive environment. However, you must develop the ability to understand and deal with complex global reality. Thus, the global mindset is in competitive premise for global leaders and organizations because it facilitates an understanding of how things are done, the psychic distance decreases and facilitates connections between local and global.
\end{abstract}

(C) 2018 Internext | ESPM. All rights reserved!

Para citar este artigo:

Mozzato, A. R.; Grzybovski D. (2018). Global mindset: Premissa para desenvolver vantagem competitiva em mercados internacionais. Internext - Revista Eletrônica de Negócios Internacionais, 13 (1), 77-89. DOI: http://dx.doi.org/ 10.18568/1980-4865.13177-89

Para acessar este artigo: http://dx.doi.org/10.18568/1980-4865.13177-89 